\title{
EXPERIMENTAL PEDAGOGY IN FRANCE. ${ }^{1}$
}

\author{
G. VATTIER, \\ Cniversity of Caen, Franoe.
}

Scientific pedagogy, or paidology, as it is also called, has succeeded to the old pedagogy, to the pedagogy of tradition. Experimentation, which has pushed its way into all the sciences one after another, was bound to make its appearance in the science of education. It is natural that the progress made by the borderland sciences as the result of experiment should have roused pedagogy to new activity, opening to it a new pathway. Pure theory, abstract conceptions, had to give place to precise measurements; the results obtained by psychology and physiology have penetrated pedagogy, infusing into, it new life and rendering it scientific and rational. Scientific pedagogy is now firmly established.

To the Americans unquestionably belongs the credit for the new trend given to pedagogy. They call it "child-study," and even today they take the front rank in this science. But Germany, which holds second place, follows them closely. In France, pedagogy, which is regarded with ever-increasing favor, has progressed very rapidly in the past few years, not only in point of laboratory researches, but also in respect to practical applications. I shall endeavor to show in detail the attempts which have. so far been made in France to develop experimental pedagogy-attempts which might have been much more numerous if less prejudice or indifference and more boldness and initiative had been manifested.

Up to 1898 researches were carried on only in the laboratory of the Sorbonne, and even these were not devoted exclu-

\footnotetext{
${ }^{2}$ Translated from the author's manuBcript.-J. C. B.
} 
sively to pedagogy. In that year, however, the conncil of the University of Lille decided to establish a laboratory, which was placed under the direction of M. Lefèvre, professor in that university, and which, according to the ideas of the latter, should be "not merely a school where students come to be instructed in truth already discovered, but a workshop in which we shall busy ourselves with formulating and solving a vast number of problems connected with the psychology of childhood and its immediate applications to pedagogy" (11).

In $1905 \mathrm{M}$. Alfred Binet, director of the laboratory of the Hautes Etudes at the Sorbonne, established in a primary school at 36 rue Grange aux Belles, Paris, a laboratory of experimental pedagogy ir order to "infuse into school instruction the results of the most recent pedagogical researches,"-results which up to that time had been known only to specialists (9). The following is a brief resume of some of the investigations undertaken:

Intelligence has been measured by means of a series of tests constituting what M. Binet and his collaborator, Dr. Simon, have called a "metric scale of intelligence." The first and best of all the tests employed consists of showing a picture to a child and having him name the objects represented in it. We thus discover what has impressed him most, what has been his controlling idea, what is the degree of his mentality, how he perceives, interprets and reasons. Moreover, this test has the enormous advantage of amusing the children and of readily calling forth responses from them. The replies naturally vary according to the age of those experimented on. The older they are the more objects they name, the more accurately they describe the persons and comment upon the things they see. The following will serve as examples of other tests. At the age of four years the children are asked to name and define certain objects placed before them, to compare weights, to copy a square, to point to the right or left ear. At a more advanced age they are 
asked to read, to tell their age, to give the number of their fingers, to draw a rhomboid, to pick out a coin, to name the days of the week and the months of the year. At 11 years of age they are required to criticise sentences which contain nonsensical statements, to repeat the greatest possible number of words in a given time, and to define certain abstract terms.

The principle that governs this scale of intelligence is evident from the preceding: It is to arrange a certain number of tests of increasing difficulty, tests which shall be as rapid and accurate as possible, try them on a large number of children of different ages, note the results obtained, and select those tests which succeed for a given age and in which younger children fail. In this manner a metric scale of intelligence has been constructed which enables one to determine whether the subject has the intelligence of his age, or is retarded or advanced. Experiments were made not only on elementary school children, but also on adolescent boys and girls, and on soldiers. (8, and 4, p. 124ff.)

By an analogous procedure MM. Binet and Vaney measured the degree of learning, the knowledge, of children; for this they devised a system of questions of the same general tenor throughout. The degree of learning is compared with that of the average child of the same age and the same social condition, and the result obtained is transformed into a notation indicating whether the knowledge of the child is normal or not. $(4$, p. $23 \mathrm{ff}$.)

In like manner investigations have been made in regard to memory. Pictures representing various objects are shown to children for a few seconds; the pictures are then covered and the children are asked to write from memory the names of the objects seen. Another method, superior to the preceding, consists in having the children study for a definte time a selection of prose or poetry, and then asking each to reproduce what he can recall. The experiment should be tried several times, and, if the material is poetry, note should be 
made of the number of lines reproduced immediately after learning and one week later. $(4$, p. 178ff.)

For several years methods have been proposed for measuring intellectual fatigue; for example, by means of the dynamometer. (6.) Attempts have been made to determine the branch of study causing most fatigue, the influence of physical work on mental fatigue, and the t5pes of fatigue; while the problems involved in the recovery from fatigue have also been successfully attacked. (12, p. 35ff.)

On the important subject of aptitudes almost no investigations have been made. M. Binet has studied two celebrated calculators, Diamandi and Inandi, and has made some observations on different types of intelligence: the reflective and the intuitive, the objective and the subjective, the practical and the literary. He finds himself opposed to the view of Thorndike on the one hand, for whom mind is only a jumbled collection of juxtaposed and quasi-independent faculties, and to that of Spearman on the other, who maintains that intelligence is unitary, that there is within us a faculty which deserves the name of general intelligence, and that there is a correspondence between the degree of even our most widely separated activities. - According to $\mathrm{M}$. Binet the truth lies midway between these extremes. It is certain, he says, that one never finds an almost complete independence between one subject of instruction and all other subjects. On the other hand there are no inverse corrolations. Excellence in one subject does not imply weakness in another. Finally there exists a faculty which acts in opposition to aptitude, i. e. general application to work. " The "dunces," according to Binet, are only children whose aptitudes have been misunderstood and who are fitted for, and show themselves successful in, manual labor. The idlers whose slothfulness is

${ }^{2}$ Aptitude means excellence in a particular line. But through close application to different kinds of work a general ability of attacking a subject is developed which tends to equalize the differences in accomplishment due to specific aptitudes.-Trans. 
due to moral causes are a negligible quantity. Their indifference is due either to weakness of intelligence or memory, or to weakness of constitution. $(4$, p. $237 \mathrm{ff}$.)

But it is not sufficient to examine the mental condition of children. It is not less useful to know their physical condition; for, as M. Binet says, the failures of pupils are often explained by their lack of nourishment, and every one knows how close is the bond between the physical and the moral. Accordingly the height of pupils has been measured, their weight determined, their biacromial ${ }^{2}$ diameter taken, and their cranial volume computed. Their muscular strength has been measured by the dynamometer and their lung capacity by the spirometer. Of especial importance are the frequent and careful tests to determine whether the children's vision is normal or defective. At the demand of $\mathrm{M}$. Binet, and in conformity with the report of $M$. Bonnaric, inspector of the Academy, M. Liard, Vice-Rector of the Academy of Paris, ordered in October, 1907, that the "optometric scale" devised by MM. Binet and Simon be used by the instructors in the primary schools of the departments around Paris to determine the condition of the children's vision. The number of pupils whose vision is abnormal has been found to be considerable. It would be no less useful to know the auditory acuity of school children, since, if we are to believe the most recently published statistics, fully $75 \%$ of the pupils in France are partially deaf. (2.) Finally, a very happy idea of Dr. Legendre, which he would like to see realized in the whole of France, is a system of individual health cards containing all the information furnished by periodical physical examinations of pupils, and constituting a permanent health record. (9.) It would be desirable to have a similar plan worked out from the intellectual point of view.

But here a question arises which we cannot pass over in silence. Whose duty is it to make all these tests? M. Binet,

2 The distance between the extremities of the two shoulder blades.-Trans. 
who, like M. Compayre, Inspector General of Public Instruction, has unceasingly encouraged psychological experimentation among teachers, is of the opinion that they alone should assume this task. Only in exceptional cases should and could the physician be called in. By no means does M. Binet overlook the criticisms made by William James; but psychological knowledge ought not to harm those who teach, and however inept teachers may be at the beginning, they are in a position to rapidly acquire an amount of knowledge in this subject sufficient for them to give a good account of themselves in experimenting on the pupils entrusted to their care. Among the majority of teachers (unfortunately there are some exceptions) we find a great desire to assimilate these new theories and much good will in applying them. Their great need is better training; but one is justified in being very optimistic, after having seen'the work done by teachers of abnormal classes.

Besides these tests numerous investigations have been made by $M$. Binet on the consumption of bread in connection with intellectual work (5); by MM. Binet and Henri on the memory of words and phrases (7);' by the "Société libré de létude psychologique de l'enfant" on rewards and punishments, lying, pupils' plays, undisciplined and rebellious children, and on the measure of memory. At the initiative of the same society M. Malapert has studied the emotion of hatred in children. (14.) M. Chabot, professor of the science of education at the University of Lyons, has undertaken several investigations in that city, among others on the variations of attention, on the difference of mental fatigue in children on different days of the week, and on the subjects preferred by pupils. (5.) An investigation similar to the latter was made in the schools of the north by M. Lefèvre and included 37,000 children. (16.) Researches have been undertaken on the physical and mental condition of pupils and on laggards. M. Larguier des Bancels has studied methods of memorizing, M. Binet, children's fears, (3) and M. Vaschide, 
the influence of prolonged mental work on the rate of the pulse (17). Some of these investigations have been carried on by the questionnaire method. If all have not given conclusive results they at least show us clearly the direction in which these new studies tend. The results of these investigations have been published chiefly in the "Année Psychologique," founded in 1894 by MM. Binet and Beannis. At first paidology had only a limited space in the volume published by $\mathrm{M}$. Binet and his collaborators, but, expanding year by year, it now occupies almost half the volume. Numerous articles and collective reviews are devoted to the subject.

Moreover, chairs of the science of education have been established,-as, for example, that formerly occupied by $M$. Marion at the Sorbonne, and that of Lyons, at present held by M. Chabot,--and in 1904 educational conferences were inaugurated under the patronage of $\mathrm{M}$. Liard at the "Musée Pédagogique" in Paris. Finally, in 1899 the "Société libre de l'étude psychologique de l'enfant" was established in Paris by $M$. Buisson, professor of the science of education at the Sorbonne, and deputy of the Seine, and placed under the patronage of MM. Ribot, professor at the College de France, and Bédorez, director of primary instruction. M. Binet is its president. This society is composed of physicians and members of the superior, secondary and elementary teaching staff. The members meet at stated periods to report on their experiences or to undertake collective investigations on special aspects of pedagogy. This organization has been called a "co-operative society for work," and comprises different committees, each of which concentrates its attention on a particular problem. Five times a year it publishes a bulletin in which are reported all the results of the investigations undertaken.

To the condition of abnormal children the attention of French educators was early directed. Indeed to France belongs the honor of having first established the principles for the education of defectives, and she it was who made the 
first attempts at the practical application of those principles. Later she fell behind other countries in the active pursuit of these investigations, and it is only in recent years that she is beginning to regain the position which she formerly held. In 1904 a commission was named by the Minister of Public Instruction for the purpose of considering measures which should provide for abnormal children such education as would be suitable and profitable for them. Certain establishments for retarded children had already been founded by private initiative, as that of Dr. Bourneville, for example, and the Board of Charities had established some schools in hospitals for abnormal children, the most important of which is the Salpétrière. In 1905 two classes for abnormal girls were inaugurated in the Department of the Seine at Paris, and a class for boys and one for girls at Lavallois-Perret. These special classes, called "improvement" classes, were intrusted to trained teachers who had made a study of the special pedagogy of defectives. In the experimental class started in a primary school in Paris the defectives are not separated from the normal pupils; the latter act as "little mothers" for the young defectives. Older pupils act as monitors, remaining almost the whole day in the class of abnormals and helping the sounger ones. A child who has served as monitor does not return for a month or two, in order not to take away the spontaneity of the normal children nor to spoil the defectives. Twice a week the monitors come to give individual instruction to their pupils. Each little teacher serves for a fortnight, and at the end of her period of service she writes a report of two or three pages on what she has observed in connection with her pupil. The following fortnight she is replaced by another, in order that the eager but short-lived zeal of these young tutors may not have time to become exhausted. Of course, this organization is only possible with the very attentive collaboration of the director. $(4$, p. $334 \mathrm{ff}$. 
The chief aim in the training of defectives is to arouse emulation, and the method of accomplishing this has been called mental orthopedy, in comparison with physical orthopedy for the correction of bodily defects. For this purpose we begin with exercises in immobility; the pupils stand motionless as statues for perhaps one minute once a day. Then they are asked to perform exercises demanding motor control, such as carrying plates full of water. An exercise frequently used is the strength test with the dynamometer. Before each trial, in order to stimulate the pupil, the result of the preceding trial is called out, and while the aim is not to increase the physical strength of the child but to teach a lesson in putting forth effort, it is soon seen that the average of the pressures steadily increases. The objects continually kept in view in the training of defectives are stimulation of attention, memory, perception and will, inculcation of lessons of discipline, teaching the children how to learn rather than trying to increase their knowledge,--in short, making them active. $(4$, p. $150 \mathrm{ff}$.

Contrary to the old pedagogy, which endeavored to establish an ideal type of pupil and to force every child to conform to this fictitious type as closely as possible, it has been found preferable to estimate the pupil's progress by a comparison with his own previous standing. One cannot too highly praise M. Boitel, director of the Ecole Turgot at Paris, who conceived the idea of constructing graphs as a stimulus to individual emulation. Each reek the child traces the curve of his progress from data which he has obtained in the course of his daily work. The ascending, horizontal or descending nature of the curve indicates his standing. (12, p. 71-72.) It is to be hoped that these graphs, successfully employed in classes for defectives, will be more generally used with all classes of pupils. They are already being introduced into a number of institutions.

These early efforts were attended with excellent results, and had a most favorable effect ppon the educational prac- 
iice of the country. In 1907 two classes for defective boys were opened at Bordeaux at the initiative of Rector Thamin. In the same year, following the meeting of a commission organized under the presidency of Senator Leon Bourgeois for the purpose of studying the means of securing primary instruction for all abnormal and defective children, a bill dealing with this subject was introduced in the chamber, and on April 15th of last year a law was enacted relative "to the organization of 'improvement' classes in public elementary schools, and of autonomous 'improvement' schools for defective children." There was indeed great need of such a law co secure a stricter enforcement of the compulsory education measure of March 28, 1882, particularly since the preceding laws applied to normal children exclusively. It is superfluous to point out the value of instruction especially adapted to defectives, both for their own good and for that of society. Besides, the studies made on them, constituting what has been called "pathological pedagogy," may be of great advantagr" to normal children, just as the medical clinic throws light upon the normal conditions of health.

The most important and most interesting provisions of the law are the following: The annexed classes are to receive children from 6 to 13 years of age. The autonomous schools, since they include part-time and full-time boarding schools, may retain their pupils until 16 years of age. No class is to include children of both sexes, but the autonomous schools may maintain two sections, one for boys, the other for girls, under the same direction. The pupils shall be given a medical inspection at least once each semester, and the observations shall be entered in a book showing the mental and physical history of each individual. A commission composed of the primary inspector, a director or master of a special school and a physician shall determine what children may not be admitted to or kept in the public primary schools and may authorize their admission to a special class or a special school. Finally, a committee of patrons shall be appointed for each 
special school, constituting a kind of administrative council. (10.) The teachers must have obtained the "certificate of fitness for teaching retarded or defective children." Candidates qualify by a year's residence in a special establishment and a written examination which tests the candidate's knowledge of the physiology, school hygiene, psychology and pedagogy of defectives. The following indicates the field covered by the examination for this certificate: General characteristics of defective children.-The conditions which give rise to idiocy, imbecility and feeble mindedness.-External appearance of defectives.-Sense organs.-Instincts.-Movements and volition.-Language.-Intelligence and special aptitudes.- Brief outline of medical treatment and hygiene.Education.-Internal organization of schools.-Courses of study.-Utilization of defectives.-Struggle against the causes. (13.)

As to the organization of these classes the number of pupils admitted to a single section shall be about 15 , increasing to 20 in exceptional cases, but never exceeding this number save for certain physical and manual training exercises. Instruction shall be given every day in the week except Sunday and a half day on Tuesday. The time shall be divided as follows:

$\begin{aligned} 8: 00-9: 30 & \text { Recitation. } \\ 9: 30-10: 00 & \text { Recreation. } \\ 10: 00-11: 30 & \text { Recitation. } \\ 1: 30-3: 00 & \text { Recitation. } \\ 3: 00-4: 00 & \text { Recreation. } \\ 4: 00-5: 00 & \text { Recitation. }\end{aligned}$

Each recitation shall be broken by a short intermission. (1) It will be well to give the course of study entire, as well as the accompanying instructions.

\section{COURSE OF STUDY.}

Paper folding, box making, measuring, weighing, construction and joining in cardboard and wood. 
Singing.

Supervised plays and games.

Walking, and working in the garden.

Free drawing, copying, and modelling in clay.

Exercises in pronunciation and articulation.

Rudiments of reading and writing, with attention to the mechanics of the activities involved. Ask numerous questions on the meaning of words, the why and the how of things.

First exercises in number. Counting from 1 to 10,10 to 20,20 to 50,50 to 100 , etc. Have the pupils handle and combine concrete objects. In the later years teach them computation, i. e. addition, subtraction, and multiplication of simple numbers, always making use of concrete objects.

The elements of geography. Study the shape and the details of the earth's surface, beginning with the topography of the garden, the school, the district, etc.

Object lessons : the study of ordinary objects placed before the children. Describe their color, form and use. Make use of frequent repetitions.

Lessons in practical life. Tell stories, anecdotes and short biographies, and have the children relate them in answer to questions. From these stories draw lessons of practical morality.

Beginning of instruction in the simplest tasks of the workshop and the garden. Special gymnastic exercises.

\section{GENERAL INSTRUCTIONS.}

Teachers are to follow the program of the primary schools in so far as it is adapted to the abilities of their pupils. Very frequently they will have to rest content with reading, writing and the elements of number. They will endeavor to gain and hold attention by the attractiveness of what they show and say, and by the variety and novelty of the exercises. They are to use word for word recitations only with discretion, and are to avoid definitions, rules and formulae. They are to make sure that pupils use in recitation only those words 
and phrases whose meaning is understood. They will very frequently have recourse to object lessons. Instruction shall be given by the direct presentation of objects, by pictures, and by familiar stories which direct the attention of the children to the observation of action and of life.

Particular attention shall be paid to the following exercises :

1. Singing and music, of which defectives are usually very fond.

2. Exercises in language and articulation, to correct the faults of pronunciation usually frequent in this class of children.

3. Simple and rational gymnastics, avoiding all trace of athleticism, and, where possible, making use of a musical accompaniment to rhythmatize the movements.

4. Plays and games of speed and skill, organized and directed by teachers so that the apathetic and obstinate children will not be isolated from their comrades.

5. Lessons in practical life, such as will put the defectives in a position to support themselves and adapt themselves to their surroundings. The smallest children should be taught to wash and dress themselves. and to have good manners at table; the older ones should be taught how to behave in company, to write a letter, to count their money, to save it, and to find their way about; the most intelligent should be taught some ideas of elementary hygiene, and especially the rules of morals, as these are particularly important for young girls of weak intelligence, who are the more exposed on account of their feeble-mindedness.

6. Manual training. The aim of the "improrement"' schools is not merely to secure for defective children the instruction to which they have a right, but to prevent their becoming a burden on society. Thus their instruction in manual training should be clearly directed toward apprenticeship and its concrete applications. Especially in the separate "improvement" schools, which keep their pupils until they are 16 and 
18 years of age, should manual training be developed. ${ }^{1}$

In the rural districts the pupil should be directed preferably to agricultural pursuits. For this reason it is desirable that a school garden should form a part of the equipment of every "improvement" school.2

In urban communities the workshops should be conducted with a view to a rational and complete apprenticeship in accordance with local needs. Simple occupations which can be pursued anywhere are the best, such as woodworking, iron work, garment making, shoemaking, embroidery, etc., taking care that the trade chosen be completely learned. ${ }^{3}$

From the preceding discussion one can see how much progress pedagogy has made in France in the last few years, and how greatly the scope of its activity has been broadened. The movement is progressing methodically, though too slowly. Its advance is due in great part to $M$. Binet, whose name I have mentioned so often in the course of this article, and who is at present the uncontested chief of the new pedagogy in France; but in spite of his efforts, in spite of the efforts of his collaborators and of other men not less eminent, there still remains much to be done, especially in the way of practical applications, and it is just in order to further the move-

'Half the time, sometimes more, is to be devoted to exercises in manual labor. It is necessary to catch the child's attention, to stimulate and perfect his powers of imitation, then by observation, by reflective analysis of his own and of the teacher's movements, and by the examination of his tools, their proportions, and their relation to the task in hand, to develop his judgment, so that when he is confronted by a new task an appeal may be made to his memory and to his reasoning powers.-Instructions relative to special schools. Bulletin de l'Instruction Publique, 28 Aont, 1909.

- In rural localities the children are to be given special training in the work of gardening and agriculture. These are the occupations which they will prefer and in which they will succeed best, and in these they wiil most readily find employment when they leave the school,-Ibid. Bulletin de l'Instruction Publique, 28 Aout, 1809.

- In the urban centers one or more workshops are always to be connected with the school. The trades chosen should be the best known and the most easily learned,-those whose manufactured products can be most readily disposed of in the region.-Ibid. Bulletin de l'Instruction Publique, 28 Aout, 1909. 
ment of pedagogy in this direction that $\mathrm{M}$. Binet has recently written his very interesting and authoritative book Les idees modernes sur les enfants, from which I have so freely borrowed.

In conclusion, let me express the hope that the applications of pedagogical research may become more numerous from day to day, that the number of those who contribute to spread these ideas may increase, and that their efforts, so worthy of interest, may be crowned with well deserved success.

\section{REFERENCES.}

1. Arrete du 17 dout, 1909. Bulletin de l'Instruction Publique, 28 Aout, 1900

2. Binet. Oauserie pédagogique. Annee Psychologique, 1908.

3. Binet. La peur chez les enfants. Annee Psychologique, 18!15.

4. BLiET. Les Idées modernes sur les enfants. Paris: Flammarion, 1900.

5. BINET. Nouvelles recherches sur la corsommation du pain dans ses rapports avec le travail intellectuel. Annee Psychologique, 1809.

6. BINET. Recherches sur lo fatigue intellectuelle scolaire et la mesure qui peut en etre faite au moyen du dynamomilre. Annee Psychologique, 1905.

7. BiNet et HeNRI La mémoire des mote. BHNET eT Hexri. La mémoire des phrases. Annee Psychologique, 1894.

8. BINET ET STMON. Le léveloppment de l'intelligence chez les enfants. Annee Paychologique, 1908.

9. Binet, Simon et Vanet. Pédagogie scientifique. Annee Psychologique, 1908.

10. Bulletin de l'Instruction Publique, ler Mai, 1009. Texte de la loi.

11. Bulletin de l'Universite de Lille, Novembre, 1898.

12. Ed. Clapabede. Psychologie de l'enfant et pédagogie expérimentalc. Genève: Kündig, 1905.

13. Décret du 14 Aout, 1909. Bulletin de l'Instruction Publique, 28 Aout, 1909.

14. Malapert. Enquete sur le sentiment de la colère chez les enfants. Annes Psychologique, 1902.

15. Rerae Pédagogique, Avríl, 1899.

16. Rerue Pédagogique, Janvier, 1900.

17. VABCHIDE. Influence du travail intellectuel prolongé sur la vitesse du pouls. Anné Psychologique, 1807. 